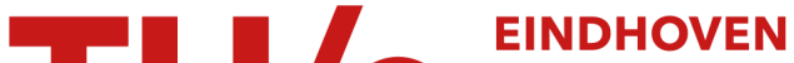 UNIVERSITY OF TECHNOLOGY
}

\section{Scalable InP integrated wavelength selector based on binary search}

\section{Citation for published version (APA):}

Calabretta, N., Stabile, R., Albores Mejia, A., Williams, K. A., \& Dorren, H. J. S. (2011). Scalable InP integrated wavelength selector based on binary search. Optics Letters, 36(19), 3846-3848.

https://doi.org/10.1364/OL.36.003846

DOI:

10.1364/OL.36.003846

Document status and date:

Published: 01/01/2011

\section{Document Version:}

Accepted manuscript including changes made at the peer-review stage

\section{Please check the document version of this publication:}

- A submitted manuscript is the version of the article upon submission and before peer-review. There can be important differences between the submitted version and the official published version of record. People interested in the research are advised to contact the author for the final version of the publication, or visit the $\mathrm{DOI}$ to the publisher's website.

- The final author version and the galley proof are versions of the publication after peer review.

- The final published version features the final layout of the paper including the volume, issue and page numbers.

Link to publication

\section{General rights}

Copyright and moral rights for the publications made accessible in the public portal are retained by the authors and/or other copyright owners and it is a condition of accessing publications that users recognise and abide by the legal requirements associated with these rights.

- Users may download and print one copy of any publication from the public portal for the purpose of private study or research.

- You may not further distribute the material or use it for any profit-making activity or commercial gain

- You may freely distribute the URL identifying the publication in the public portal.

If the publication is distributed under the terms of Article 25fa of the Dutch Copyright Act, indicated by the "Taverne" license above, please follow below link for the End User Agreement:

www.tue.nl/taverne

Take down policy

If you believe that this document breaches copyright please contact us at:

openaccess@tue.nl

providing details and we will investigate your claim. 


\title{
Scalable InP integrated wavelength selector based on binary search
}

\author{
Nicola Calabretta, * Ripalta Stabile, Aaron Albores-Mejia, Kevin A. Williams, and Harm J. S. Dorren \\ COBRA Research Institute, Eindhoven University of Technology, P. O. Box 513, NL-5600 Eindhoven, The Netherlands \\ *Corresponding author: n.calabretta@tue.nl \\ Received July 13, 2011; revised September 2, 2011; accepted September 2, 2011; \\ posted September 7, 2011 (Doc. ID 150921); published September 26, 2011

\begin{abstract}
We present an InP monolithically integrated wavelength selector that implements a binary search for selecting one from $N$ modulated wavelengths. The InP chip requires only $\log _{2} N$ optical filters and $\log _{2} N$ optical switches. Experimental results show nanosecond reconfiguration and error-free wavelength selection of four modulated wavelengths with $2 \mathrm{~dB}$ of power penalty. (C) 2011 Optical Society of America
\end{abstract} \\ OCIS codes: $130.7408,200.4740,060.6719$.
}

High-speed and fast reconfigurable next generation optical networks are currently investigated to handle the ever increasing growth of Internet traffic. Fast reconfigurable wavelength selectors (WSs) that allow for operation on a large number of wavelength channels, with low cross talk and low optical signal-to-noise ratio (OSNR) degradation, and with fast dynamic response (in the order of nanoseconds) are essential subsystems for implementing reconfigurable WDM core and metro networks, optical packet switched networks, and ultrafast optical signal processing. Compact, low-power integrated solutions are also important for the WS scalability. Several tunable filter based WSs were investigated in [1-5]. However, high losses [1,3,5], low speed tuning [2], and narrowband operation $[\underline{4}]$ are critical issues. In [ㅎ], the high losses prevent practical utilization of the all-polymer WS based on electro-optic polymer switch array between two polymer arrayed waveguide gratings (AWG).

Lossless InP monolithically integrated AWGs in combination with optical switches based on semiconductor optical amplifiers (SOAs) were successfully demonstrated and applied to demonstrate fast optical packet switching [7]. However, the number of active components in the WS scales linearly with the number of channels $N$. In [8], a solution was demonstrated that scales as $2 \times \sqrt{ } N$. However, for a large number of channels the number of switches still becomes substantial.

Here we present an InP monolithically integrated WS based on a binary search algorithm that requires only $\log _{2} N$ switches to select $N$ wavelengths. The optical switches are based on SOA technology that enables nanoseconds speed operation and lossless operation. Experimental results show error-free wavelength selection of four $10 \mathrm{~Gb} / \mathrm{s}$ modulated signals at distinct wavelengths by using two optical switches with a power penalty of less than $2 \mathrm{~dB}$.

The WS based on a binary search is schematically shown in Fig. 1(a). Half of the incoming channels are selected at each node according to the binary state of the node control. Thus, after the first node there will be $N / 2$ channels remaining, then $N / 4$ channels after the second node, and so on until one channel is univocally selected. The amount of required nodes and controls to select a distinct channel is $\log _{2} N$. Without losing generality, Fig. 1(a) shows as an example the operation of the WS for eight wavelengths $\left(\lambda_{1}, \ldots, \lambda_{8}\right)$. The WS requires three nodes, which is controlled by a binary control. For control signals " $1 \quad 0 \quad 1$ " for the three nodes, the WS will select the $\lambda_{6}$. At the first node $\lambda_{5}, \ldots, \lambda_{8}$ are selected, at the second node $\lambda_{5}$ and $\lambda_{6}$ are selected, and at the third node $\lambda_{6}$ is selected.

The WS based on binary search algorithm can be effectively implemented in the optical domain, as shown in Fig. 1(b). Each of the $\log _{2} N$ nodes selects half of the incoming channels by using a periodic filter (PF) and an optical switch. The PF spectrally divides half of the channels to output port 1 (black solid line) and the other half to the output port 2 (red dashed line). The optical switch forwards channels from either port 1 or 2 as instructed by the binary control. Note that the PFs at the $i$-th node have a free spectral range $\mathrm{FSR}_{i}=\mathrm{BW}_{\mathrm{ch}} \times N / 2^{i}$ with $i=1, \ldots$, $\log _{2} N$, and $\mathrm{BW}_{\mathrm{ch}}$ the channel bandwidth. This guarantees that the $\mathrm{PF}$ at the following node spectrally partitions half of the incoming channels to port 1 and the other half to port 2.

Figure 1(b) shows the WS operation with eight channels. Given " $1 \quad 0 \quad 1$ " as binary controls, $\lambda_{6}$ is selected by the WS circuit. Indeed, at the first node the PF in combination with the optical switch selects $\lambda_{5}, \ldots, \lambda_{8}$. At the second node, the PF with FSR/2 separates the $\lambda_{5}, \lambda_{6}$ at port 1 and $\lambda_{7}, \lambda_{8}$ at port 2 and the optical switch selects $\lambda_{5}$, $\lambda_{6}$. At the third node, the PF with FSR/4 separates the $\lambda_{5}$ at port 1 and the $\lambda_{6}$ at port 2 and the optical switch selects $\lambda_{6}$. The example in Fig. 1 employed eight channels and required $3=\log _{2} 8$ optical switches and PFs. The

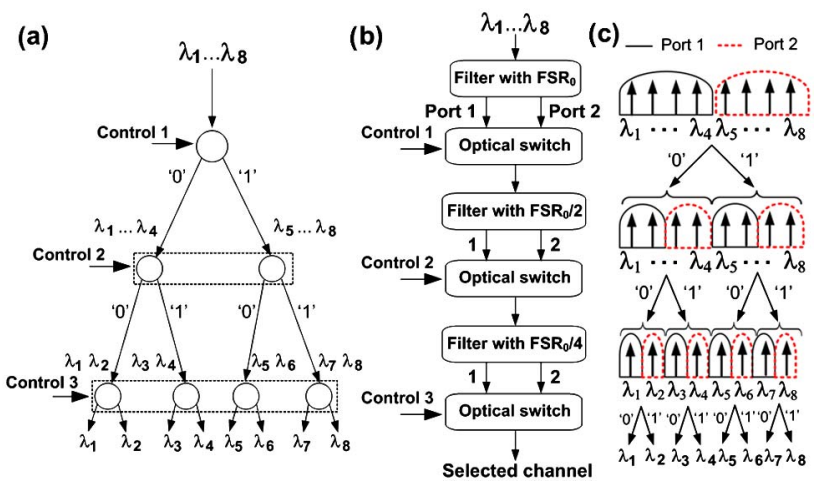

Fig. 1. (Color online) Operation of (a) the binary search algorithm, (b) the optical WS circuit, (c) transfer functions of the periodic filter with different free spectral ranges. 
operation of the WS can be generalized to $N$ channels by using $\log _{2} N$ optical switches and PFs.

As a proof of concept, we have fabricated an InP monolithically integrated WS capable to select one out of four wavelengths. The PFs were implemented by using Mach-Zehnder interferometer (MZI) filters, and each of the two optical switches consists of two SOAs driven by two complementary electrical signals, as shown schematically in Fig. 2(a).

The InP monolithically integrated WS is shown in Fig. 2(b). It includes the optical switch 1, the PF2, and optical switch 2. The PF1 was not in the integrated chip. The chip is fabricated from a four quantum well active InGaAsP/InP epitaxy with a gain spectrum covering the range $1590-1620 \mathrm{~nm}$. A three-step reactive ion etch is performed to define deep and shallow waveguides and to electrically isolate adjacent electrodes for the required operation. The total area of the integrated circuit is less than $4 \times 1 \mathrm{~mm}^{2}$. The lengths of $\mathrm{SOA}_{1}, \mathrm{SOA}_{2}, \mathrm{SOA}_{3}$, and $\mathrm{SOA}_{4}$ are 2.6, 3, 1.6, and $1.6 \mathrm{~mm}$, respectively. The MZI filter uses deep-etched waveguides. The waveguide filter arm lengths are 500 and $272 \mu \mathrm{m}$, respectively. Multimode interference couplers are employed as splitters and combiners.

The experimental setup employed to demonstrate WS operation with optical signals at different wavelengths is shown in Fig. 2. First, the static characterization of the WS chip has been performed. Lensed fibers were employed for coupling the light in/out of the chip. DC currents of $110 \mathrm{~mA}$ and $114 \mathrm{~mA}$ were applied to $\mathrm{SOA}_{1}$ and $\mathrm{SOA}_{3}$, and $27.3 \mathrm{~mA}$ and $20.2 \mathrm{~mA}$ to the two arms of the active filter. The input coupler current was $3.2 \mathrm{~mA}$ to optimize the contrast ratio while the output coupler current was $29.2 \mathrm{~mA}$ to provide gain. The SOA current at the chip output was $35 \mathrm{~mA}$. The transfer function presents a periodicity of $3.2 \mathrm{~nm}$. The $-3 \mathrm{~dB}$ bandwidth of the MZI filter was $1.1 \mathrm{~nm}$. The cross talk between channels spaced by $1.6 \mathrm{~nm}$ was around $-16.5 \mathrm{~dB}$. Cross talk and flattop passband can be further improved by using higher-order filters [9].

The static operation of the WS chip was tested by injecting four $\mathrm{CW}$ optical signals, $\lambda_{1}=1600.9 \mathrm{~nm}$ and $\lambda_{2}=1602.5 \mathrm{~nm}$ into port 1 , and $\lambda_{3}=1604.1 \mathrm{~nm}$ and $\lambda_{4}=$ $1605.7 \mathrm{~nm}$ into port 2, respectively (see Fig. 2). The optical switches in the WS chip have been electronically controlled to select a distinct CW wavelength. When optical switch 1 forwards the channels from output port 1 of the MZI filter, either $\lambda_{1}$ or $\lambda_{2}$ can be selected by the optical switch 2 according to the binary control. If the optical switch 1 forwards the channels from output port 2 of

(a)
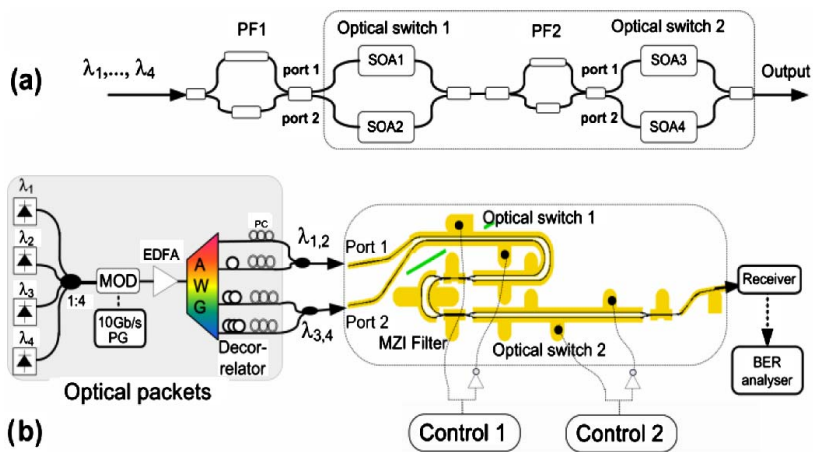

Fig. 2. (Color online) (a) Schematic and (b) experimental setup of waveguide and electrode layout of the fabricated chip.
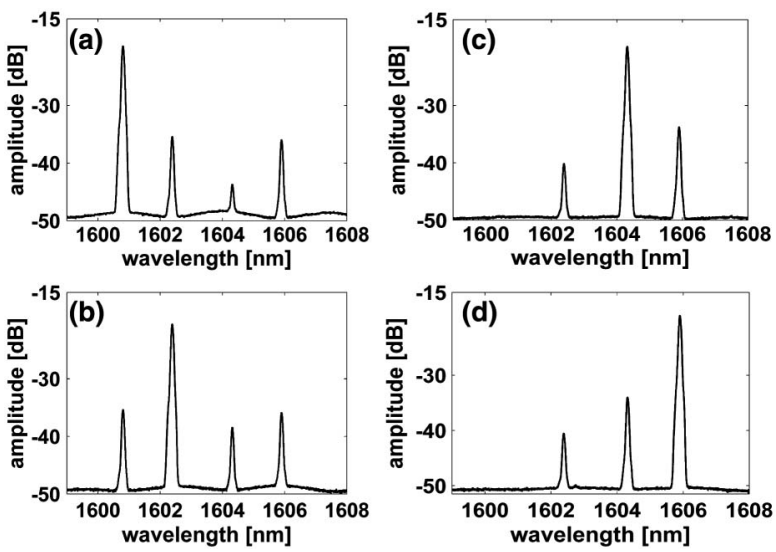

Fig. 3. Optical spectra recorded at the WS output for four different operations of the selector: (a) $\lambda_{1}$, (b) $\lambda_{2}$, (c) $\lambda_{3}$, (d) $\lambda_{4}$.

the MZI filter, either $\lambda_{3}$ or $\lambda_{4}$ can be selected by the optical switch 2 . The four measured spectra at the chip output for the four combinations are shown in Fig. 3. Those static results clearly show the WS operation. The measured cross talk was lower than $-16 \mathrm{~dB}$, and the OSNR of the selected CW signals were larger than $30 \mathrm{~dB}$. Scaling the WS operation to a larger number of channels will be limited by the OSNR degradation caused by the accumulated amplified spontaneous emission (ASE) noise of the SOAs in the chain. OSNR values exceeding $26 \mathrm{~dB}$ have, however, been measured after eight recirculating loops [10] indicating the possibility to scale to eight nodes the $\overline{\mathrm{WS}}$ and thus to select one from 256 incoming wavelengths.

We have also investigated the time response of the WS chip. We fed a CW signal into the WS and we applied an electrical pulse with $5 \mathrm{~V}$ of amplitude and a rising and falling time of 2 ns to the optical switch. Figure 4 shows the photodetected output of the WS showing a rise time and fall time of around 4.6 and $3.2 \mathrm{~ns}$ (10\%-90\% transitions), respectively. Electrical reflections are seen to lead to a dip in the time resolved gain $46 \mathrm{~ns}$ after the turn-on transient. This is expected to be eliminated by implementing high-speed drivers in close proximity to the chip.

To investigate the dynamic operation of the WS chip, we generated optical packets at $\lambda_{1}, \ldots, \lambda_{4}$ by using an amplitude modulator driven by a $10 \mathrm{~Gb} / \mathrm{s}$ pattern generator with $\mathrm{a} 2^{11}-1$ pseudo-random binary sequence interleaved with

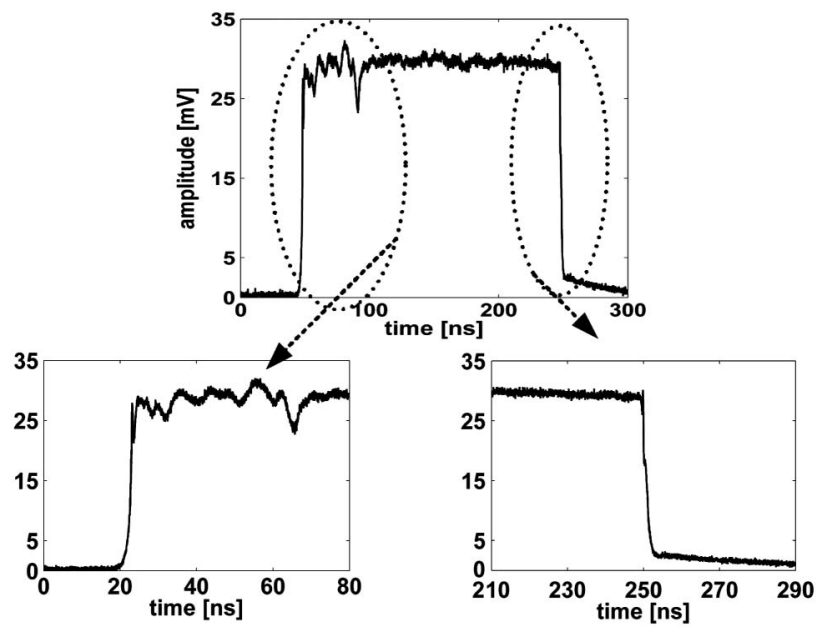

Fig. 4. Time response of the SOA of the optical switch. 


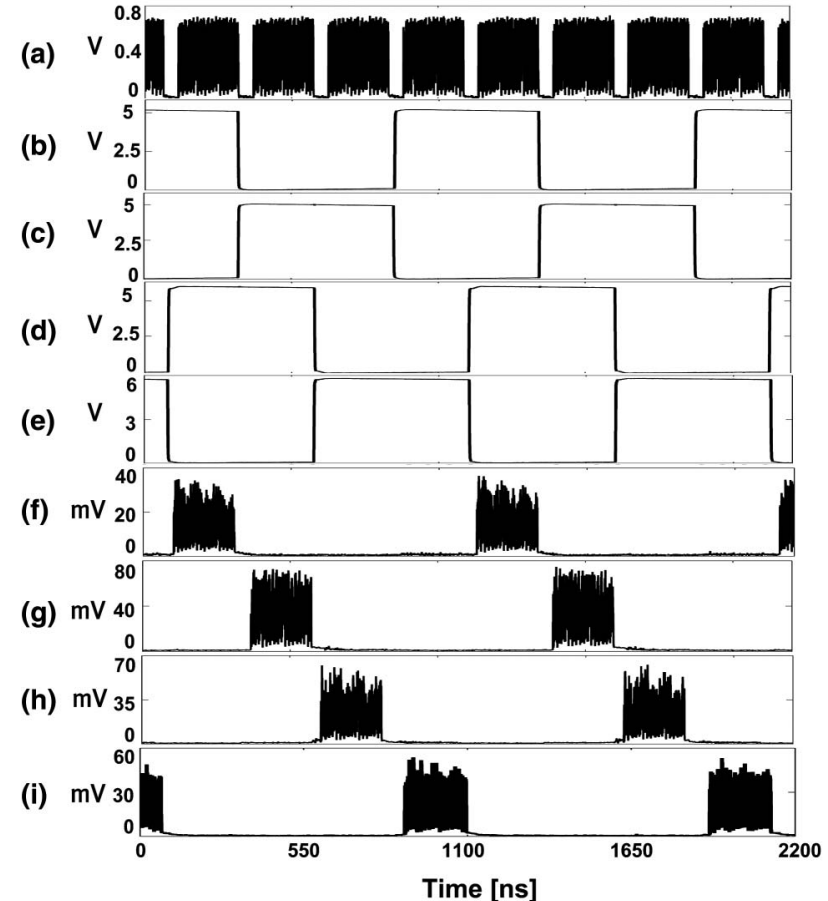

Fig. 5. (a) Input packets. Complementary controls applied to (b),(c) SOA1, SOA2 of the optical switch 1; (d),(e) SOA3, SOA4 of the optical switch 2 ; (f)-(i) WS output traces for the wavelength $\lambda_{1}, \lambda_{3}, \lambda_{2}$, and $\lambda_{4}$, respectively.

512 bits sequence of zeros [see Fig. 5(a)]. This results in a packet guard time of $51.2 \mathrm{~ns}$, which is sufficient to guarantee the response of the SOA to be flat with respect to the applied control, avoiding the dip $46 \mathrm{~ns}$ after turn-on. The colored packets were amplified, wavelength demultiplexed and decorrelated, before being fed into the WS chip. Two pairs of modulated signals $\lambda_{1}, \lambda_{2}$ and $\lambda_{3}, \lambda_{4}$ were fed into the two inputs of the WS, respectively. The optical power of each signal was $-2 \mathrm{dBm}$ at the input fiber lens. The output power was $-13 \mathrm{dBm}$ per channel. Assuming $6 \mathrm{~dB}$ /facet coupling losses, the chip losses are compensated by the SOAs. $\mathrm{SOA}_{1}, \mathrm{SOA}_{2}, \mathrm{SOA}_{3}$, and $\mathrm{SOA}_{4}$ of the two optical switches were driven by electronic control signals with $5.2 \mathrm{~V}, 5.1 \mathrm{~V}, 5.4 \mathrm{~V}$, and $5.8 \mathrm{~V}$, respectively. Note that most of the voltage is dropped across the $39 \Omega$ matching resistor between the $50 \Omega$ controller and the chip. By using a regular current source, the required voltage would be less than $1.5 \mathrm{~V}$.

Figures 5(b)-5(e) show the control signals appropriately delayed to dynamically select one distinct wavelength at a time. Figures 5(f)-5(i) report the time-domain traces for each of the four wavelengths at the output of the WS. Those traces clearly show that according to the control pattern only the one optical wavelength packet is selected by the WS. The average extinction ratio was higher than $15 \mathrm{~dB}$. The eye diagrams measured at the input and output of the WS chip are shown in Fig. 6. The eye diagram at the WS output is clearly open but it is slightly degraded due to cross-gain modulation in the SOA and noise. The bit error rate (BER) curves of the selected packets are reported in Fig. 6. The BER curve in back-to-back configuration is provided as reference. We also report the BER curve in static operation of

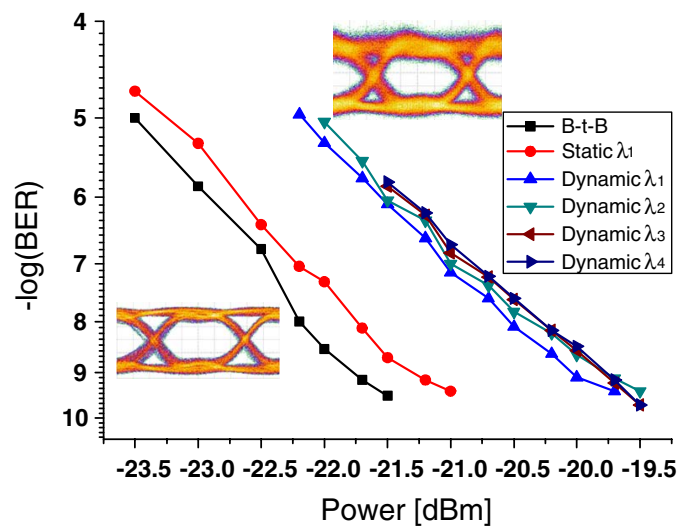

Fig. 6. (Color online) BER curves of the back-to-back and static selected wavelength at $\lambda_{1}$, and of the dynamic packet selected operation. Inset, eye diagrams of the signal before and after the WS at $\lambda_{1}$.

the WS recorded when only one wavelength $\left(\lambda_{1}\right)$ is transmitted through the WS. Error-free operation with a power penalty of $0.5 \mathrm{~dB}$ was measured. Error-free operation is also obtained for the dynamic selection of the packets at different wavelengths with a power penalty of $1.7-2.1 \mathrm{~dB}$, which is around $1.2 \mathrm{~dB}$ larger than the static case. The penalty is expected to be due to cross-gain modulation between the signals and ASE from the SOAs.

We have demonstrated a fast InP monolithically integrated WS based on a cascade of periodic filters and optical switches that requires $\log _{2} N$ optical switches for selecting $N$ wavelength signals. Experimental results show error-free wavelength selection of four modulated signals at distinct wavelengths with a power penalty of less than $2 \mathrm{~dB}$.

\section{References}

1. A. d'Alessandro, D. Donisi, R. Beccherelli, R. Asquini, R. Caputo, and C. Umeton, Opt. Express 16, 9254 (2008).

2. S. T. Chu, B. Little, J. Hryniewicz, P. Absil, F. Johnson, O. King, M. Trakalo, and J. Shanton, in Proceedings of IEEE Conference on Optical Fiber Communication (OFC) (IEEE, 2004), p. PDP9.

3. X. Lu, M. Li, R. Samarth, and L. Zheng, Opt. Eng. 46, 040508 (2007).

4. E. J. Norberg, R. S. Guzzon, J. S. Parker, L. A. Johansson, and L. A. Coldren, J. Lightwave Technol. 29, 1611 (2011).

5. E. L. Wooten, R. L. Stone, E. W. Miles, and E. M. Bradley, J. Lightwave Technol. 14, 2530 (1996).

6. J. T. Ahn, S. Park, M. H. Lee, and K. H. Kim, IEEE Photon. Technol. Lett. 16, 1567 (2004).

7. S. Khalfallah, B. Martin, J. Decobert, S. Fabre, C. Fortin, P. Peloso, I. Guillemot, J. Le Bris, M. Renaud, A. Goth, A. Dupas, L. Gilbert, and D. Penninckx, in 27th European Conference on Optical Communication (ECOC) (IEEE, 2001), Vol. 6, p. 80.

8. N. Kikuchi, Y. Shibata, H. Okamoto, Y. Kawaguchi, S. Oku, Y. Kondo, and Y. Tohmori, IEEE Photon. Technol. Lett. 16, 2481 (2004).

9. Z. Wang, S. Chang, C. Ni, and Y. Chen, IEEE Photon. Technol. Lett. 19, 1072 (2007).

10. E. F. Burmeister, J. P. Mack, H. N. Poulsen, J. Klamkin, L. A. Coldren, D. J. Blumenthal, and J. E.Bowers, in Proceedings of IEEE Conference on Optical Fiber Communication (OFC) (IEEE, 2008), paper OWe4. 